\title{
E-Business Development : A Strategic View
}

\author{
Saad Haj Bakry
}

Department of Electrical Engineering, King Saud University, Riyadh, Saudi Arabia, Email:shb@ksu.edu.sa.

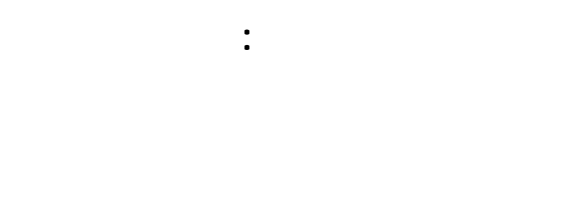

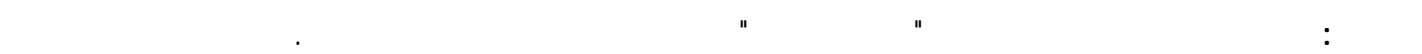

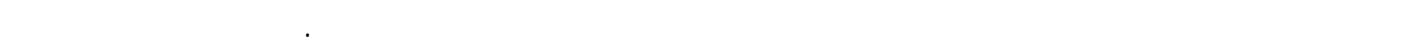

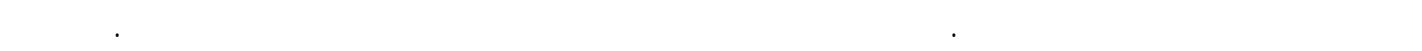

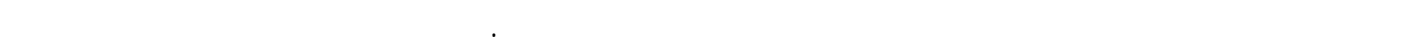

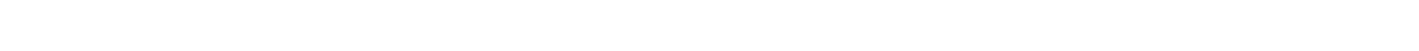

\section{Summary}

E-business is becoming increasingly important for countries, organizations and individuals, as it gives them efficiency, and as it integrates them together, and with the world at large. This paper aims at providing a strategic view of the development of e-business. It starts by identifying e-business, and by reviewing its current progress. It then presents an e-business development profile, that defines the various elements associated with it. Based on the profile, the paper then provides future development guidelines, and identifies recommended plans.

KEYWORDS: Electronic Business, Electronic Commerce, Electronic Services.

\section{Introduction}

M

any publications, including Magued et al (1998), have previously addressed the role of information technology (IT) utilization in national development, and in the promotion of the competitiveness of organizations in various countries, operating in different fields. E-business is concerned with the collective utilization of IT, and therefore it is associated with national development, and it is related to the competitiveness of organizations. The European Union (EU) Lisbon summit meeting of 15 European leaders, ending on March 24, 2000, has emphasized the importance of e-business for economic growth and for better jobs. This paper is concerned with introducing a strategic view for the future development of e-business, which may help interested organizations and countries. As a background to the subject, this section attempts to identify ebusiness, and to explore its current progress.

\subsection{Identifying E-Business}

E-business can be defined as "publishing information, and performing different types of transactions, or chains of them, electronically over Intranets, Extranets, and the Internet". This may be within organizations, or between them, and with the involvement of individual customers. The outcome would widen the availability of information, and enhance work integration up to the 


\section{SAAD HAJ BAKRY}

world level; and it would also save time, movement, space and paper, and consequently lower cost (Jamal-Aldeen et al, 2000).

In the IT emerging vocabulary, there are different terms related to e-business, generated for different purposes, as explained in the following:

- Some terms are generated to express specific functions related to a narrower concept within the e-business scope. These include: "e-government" services, "e-commerce", "e-bargain", "eauction", "e-advertisement", "e-outsourcing”, "e-procurement", "e-care” for customers, "elearning", and other function oriented "e-terms" (Economist June 26, 1999, Business Week, December 13, 1999 and Information Week April, 26, 1999).

- Other terms are concerned with providing an alternative comprehensive name to e-business. "Dynamic trade", and the "para-enterprise" have been suggested (Economist June 26, 1999).

- In addition, one new term emphasizes the IT led change in the "business environment", and suggests that "e" in the e-business is not only for "electronic" business, but it is also for a new "ecosystem". This illustrates that the transformation of business to e-business does not only require the "reengineering" of the corporation, but it may also need its "reinvention" (Economist, June 26, 1999, Hammer M, Champy J. 1993).

It can be seen from the terms and definitions above, that e-business is related to different "functions", where the term may change accordingly. It can also be seen that e-business does not only "energize" business and make it more "dynamic", but it does also generate new "environment" and "culture" for business in future.

\subsection{Current Progress}

The following are some important examples of the current development, which reflects the future potential, of e-business in different parts of the world.

- Considering the diffusion of innovation " $S$ " curve (Roger M.R., 1983), e-business in the US and Canada is about to reach the threshold "of "hyper growth". In other developed countries, like the European countries, it has already started, or expected to start, the initial stage of "slow growth" (Economist, June 26, 1999). In addition, some developing countries like Malaysia and India are considering "e-government" services (Magued et al, 1998, Information Week April, 26, 1999).

- The Lisbon summit meeting, mentioned above and described as the "dot.com" summit, emphasized the promotion of e-business "growth" in Europe, in order to close the gap with the US and Canada. Its stated goal is to build "a knowledge driven economy for economic growth and better jobs". For this purpose it stressed that European "businesses and citizens should have access to inexpensive world class communications infrastructure, and wide range of information services" (CNN.com, 2000).

- The "growth" of e-business in companies, associated with some sectors, such as computing and aerospace, has already reached the " $S$ " curve threshold of "hyper growth". In other companies of other sectors, it is in the "slow growth" stage, or under preparation to "start". In 1998 , the revenues of the inter-company trade on the Internet were estimated at around $\$ 43$ billion. It was also estimated that until 2003, the figure will double annually to reach $\$ 1.3$ trillion (Economist June 26, 1999).

- Companies are increasing their spending on IT products and services to enhance their competitiveness. In 1995, American companies in different sectors were spending " 2 to $10 \%$ " of their revenues on IT products and services. By 2005, this spending is expected to increase 


\section{E-BUSINESS DEVELOPMENT: A STRATEGIC VIEW}

and reach the range between "5 to $20 \%$ " (Business Week February 14, 2000). It should be noted that the revenues of these companies are also expected to increase making the growth of IT expenditure of a multiple nature.

- International development organizations like the World Bank (WB), and regional development organizations like the Islamic Development Bank (IDB) are supporting the drive toward e-business in developing countries. The world bank has an IT development unit that supports e-business studies, known as "infodev" at www.worldbank.org, and the IDB had explored the potential of e-business in a recent conference in Africa (Magued et al, 1998). This can be explored by developing countries to develop their e-business, and attempt to narrow the gap with the developed world.

- IT companies, such as Dell, Cisco, Sun and IBM are using e-business to promote their revenues. From this use, some companies like IBM and Sun are learning the growing ebusiness "requirements" in order to provide suitable IT products to the e-business market. Since the e-business technology is of wide IT scope, some companies, like SAP, HP, and Qwest are forming "joint ventures" to provide integrated e-business solutions. In addition, many e-business development companies are being formed in response to the market demands (Economist june 26, 1999, Business week, 13, 1999).

The above illustrates the strong drive toward the development of e-business in developed and developing countries, and in the private sector. The above also shows the interest of international and regional organizations in supporting e-business for promoting development. This drive is enhanced further by its interaction with the drive of the IT companies toward developing and improving the e-business technology. Countries and companies should now face the need to develop e-business, or risk possible isolation from the emerging new "work environment" and "business culture".

\subsection{This Paper}

This paper is concerned with supporting the drive toward e-business by presenting a strategic view for its development. The view consists of two parts: the first introduces "an e-business development profile"; and the second provides "development guidelines".

$\diamond$ The "development profile" aims at identifying the elements concerned with e-business development; while

$\diamond$ The "development guidelines" aims at exploring how to achieve such development.

The two parts together would help countries and organizations to set up plans for the development of e-business, in order to enjoy its benefits, and to be integrated with the emerging global business culture.

\section{Development Profile}

Three main elements are usually considered in technology planning: "Technology", "Organization", and "People": TOP (Technology ATLAS team 1987, Linstone HA.A, 1994). In our target profile we will add the following elements: "Development", "Strategy", and "Environment", as illustrated in Figure 1. The resulting profile, with its "six elements", can then be described as the "development STOPE" profile. This resulting name of the profile is expressive, from an e-business viewpoint, for two different reasons.

- On the one hand, to support efficiency, e-business should at one "STOPE" automatically initiate a chain of transactions that perform the sequence of needed tasks. 
- On the other hand, the continuous development of IT, would require continuous movement forward from one "development STOPE" to another, in a repeated manner, to achieve continuous competitiveness.

The six elements of the proposed profile are addressed in the following, starting with the "development" issues.

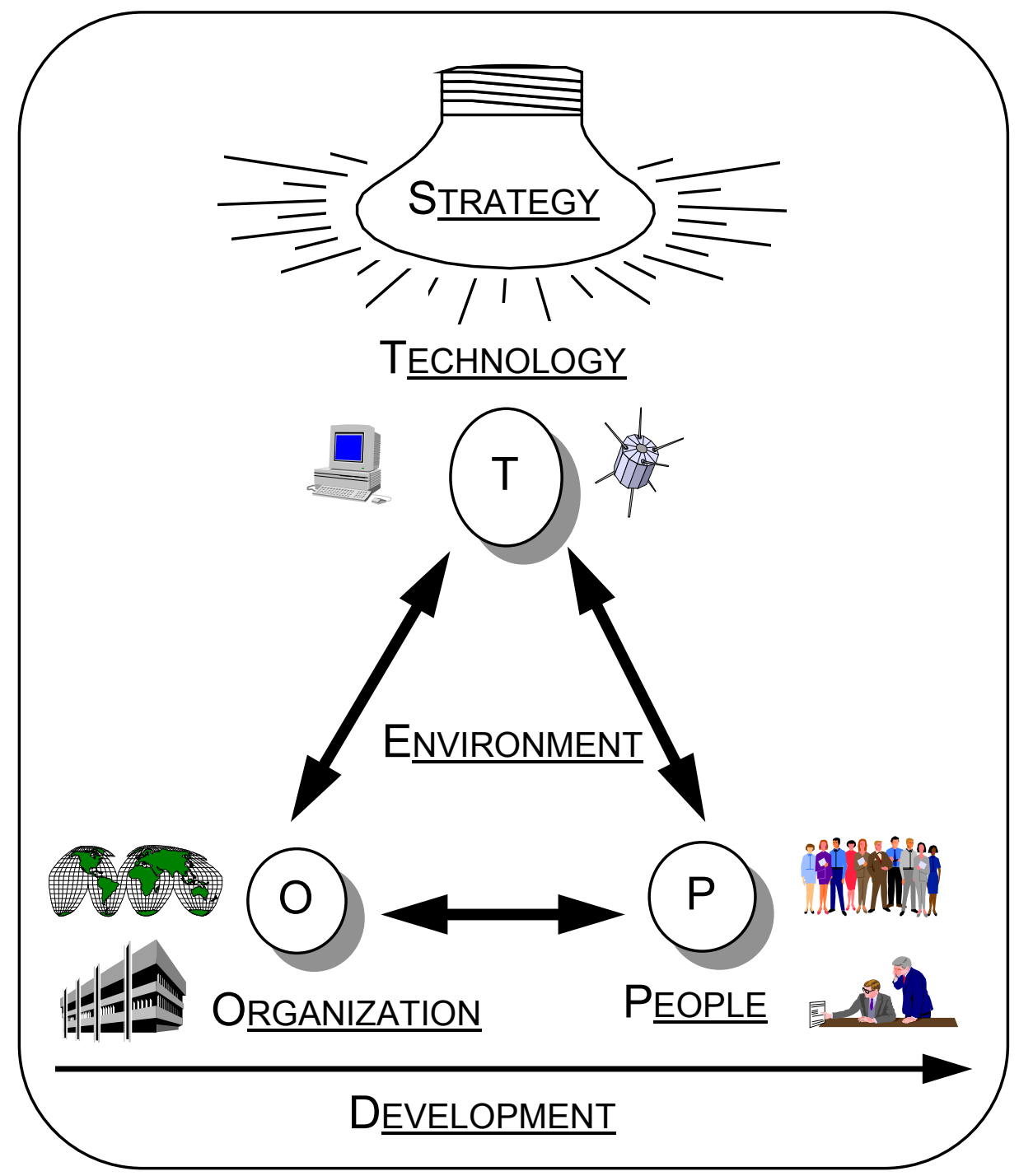

Figure 1: The elements of the "development STOPE” profile.

\section{Development}

The development of e-business would have two main "objectives". The first is concerned with the resulting business efficiency, while the second is associated with the business integration it provides among related parties. In addition, for IT companies, there is one added objective, that is promoting the IT market.

E-business development is of a "multidimensional nature", for the following main reasons.

- It is associated with different levels: the global level, the national level, and the private level, with each may be related to different sublevels.

- It is concerned with different parties, as no e-business is possible without having the right development for all the parties concerned. 


\section{E-BUSINESS DEVELOPMENT: A STRATEGIC VIEW}

- It is related to different elements as shown in Figure 1 where the development of ebusiness requires the development of its various elements.

E-business development is also concerned with "time". In this respect two issues need to be considered.

$\checkmark$ As with any innovation, the diffusion, or the development, of e-business cannot have instant multidimensional "hyper growth", as it would follow the rules of the " $S$ " curve (Economist June 26, 1999, Roger M.R. 1983), mentioned above. Investment in e-business should take this into account.

$\diamond$ However, special wide scale strategic support, like the case of the Lisbon summit (CNN.com, 2000), would accelerate development, and shorten the "slow growth" stage of the "S" curve moving faster toward "hyper growth” (Roger M.R. 1983).

\section{Strategy}

An e-business strategy provides a "basic plan" for the development of e-business. It specifies the development objectives, and determines the development directions for achieving the objectives within a given time scale. Therefore, an e-business strategy is concerned with the above e-business development multidimensional characteristics associated with different levels, different parties, and different elements on the one hand, and with its growth pattern features on the other.

An e-business strategy would depend on the party issuing the strategy, and its interest. For example, as mentioned above, the European Union, at the European level, issued its e-business strategy for the strategic objective of achieving higher economic growth, and better jobs. Its strategic direction to achieve this was to enable European businesses and citizens to access "inexpensive IT infrastructure" (CNN.com, 2000). In addition, at a company level, IBM e-business strategic direction for the strategic objective of providing suitable e-business products was to "learn by doing" (Business Week Dec, 13, 1999). It should be noted that for any e-business strategic objective, and any strategic direction, the following "TOPE" elements should be take into account in setting up strategic plans.

\section{Technology}

Technology is of course the enabler of e-business. It can be viewed according to the following four layers, as given in Figure 2.

- The bottom layer is the "communications layer", that is the core that enables networking and the integration of information services . At this layer the public and the private communications provided by various communication networks like telephone networks, data networks, highspeed ATM networks, and cellular mobile networks, would be involved.

- The next layer up is the "network layer", which enables information services, including ebusiness, to be provided at a private intra-organization level (Intranet), a private interorganization level (Extranet), and the world at large (Internet). Of course, security measures, including firewalls, provide the required protected borders between these levels.

- The third layer is the layer of "e-business services". This layer is mainly based on the "web technology", which enables e-business services to operate on Intranets, Extranets, and the Internet levels. In addition, the services would depend on the capabilities of the 
communications infrastructure, which determines the type of information that can be transferred including data, voice, and picture.

- The top layer is the layer of the "users" who can access and use the available e-business services. Depending on the given services, such users may be public, or they may be authorized private users.

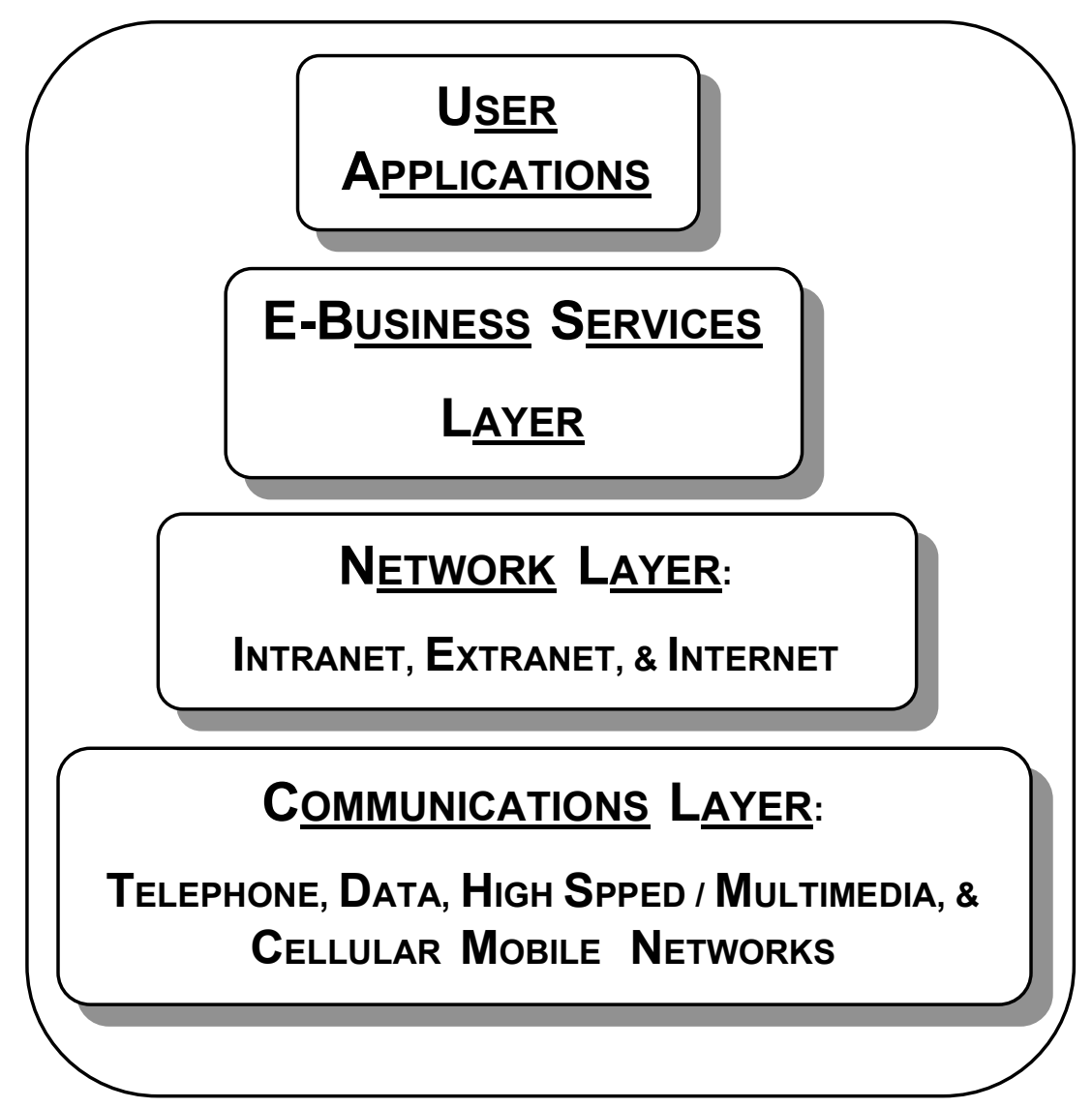

Figure2: The layers of e-business technology

The above shows that e-business depends on the communications infrastructure, the Internet, and the security needed for Intranets and Extranets. Therefore, e-business enjoys the advantages of these networks on the one hand, and faces their problems on the other. In addition, e-business services are still in their early stages of development. They still need learning and innovations. The future development of e-business would require the development of all four levels of its technology.

\section{Organizations}

The general functional view of an organization using e-business is represented in Figure 3. The view shows the levels of the e-business services, and the parties associated with each level.

$\diamond$ At the "Intranet level", e-business services involve intra-organization business transactions. The users here are the staff of the organization concerned.

$\diamond$ At the "Extranet level", e-business services involve the inter-organization business transaction, in addition to the business transactions between the organization concerned and its associated individuals. The other organizations, and the associated individuals of this levels are the partners, the suppliers, and the customers of the organization concerned. Each of these would have certain information access and interaction rights, and may be involved in a chain of 


\section{E-BUSINESS DEVELOPMENT: A STRATEGIC VIEW}

business transactions. It should be noted that the Extranet level is replacing an older technique known as Electronic Data Interchange (EDI), as it is more flexible, and of lower cost.

$\diamond$ The e-business services of the "Internet level" involves the public business transactions between the organization concerned and its potential partners, suppliers, and customers, whether organizations or individuals.

The current trend of e-business development, discussed above, indicates that most, if not all, organizations including international organizations, government departments, and private enterprises would become e-business users sooner or later, depending on their environments and businesses. Those who may keep away from e-business would face isolation, and loss of competitiveness.

Of course organizations should develop their own e-business activities, but such development depends on various other organizations, as explained in the following:

- The e-business activities, at both the Extranet and the Internet levels, do not only involve the organization concerned, but they also involve other organizations. Therefore, joint e-business development among these organizations would be needed.

- Developing e-business requires funds for building the necessary communications and Internet infrastructure. Such funds may not be available, particularly in developing countries, wishing to enter the information age. Here comes the role of the international and the regional development funding organizations like the WB, and the IDB in supporting e-business development.

- IT companies are the generators of the e-business technology which enables the e-business activities to take place. Therefore the success of these activities would depend on the success of the e-business technology products and services provided by the IT companies.

\section{People}

People, whether individuals or associated with organizations, are both the source and the target of e-business. Therefore people concerned with e-business include the following.

- Executives and politicians concerned with making decisions on the use of e-business in their organizations and countries, or on the support of e-business development.

- IT people concerned with the development and management of e-business technology and services. It should be noted here that, like the various IT industries, e-business would provide good job opportunities for those people, not only in IT companies, but also in organizations using e-business (Beck N. 1995, Business week Aug, 4, 1997).

- People using e-business, and enjoying its benefits. Those may be individuals or associated with organizations, as discussed above.

\section{Environment}

The e-business development environment is related to the state of development of the above elements: technology, organization and people. These elements are associated in turn with the interrelated issues of "knowledge", "economy", and "management", in terms of which the environment is explained in the following:

$\diamond$ Knowledge can be expressed in terms of the awareness, the interest, and the qualifications of people who are the source and the target of development. 
$\diamond$ The economy is associated with the sources of income, productivity, competitiveness, and technology infrastructure.

$\diamond$ Management is related to the work culture including the regulations and the security of the organization, or the country concerned, its intra-organization and inter-organization relationships, in addition to the vision and will of its decision makers.

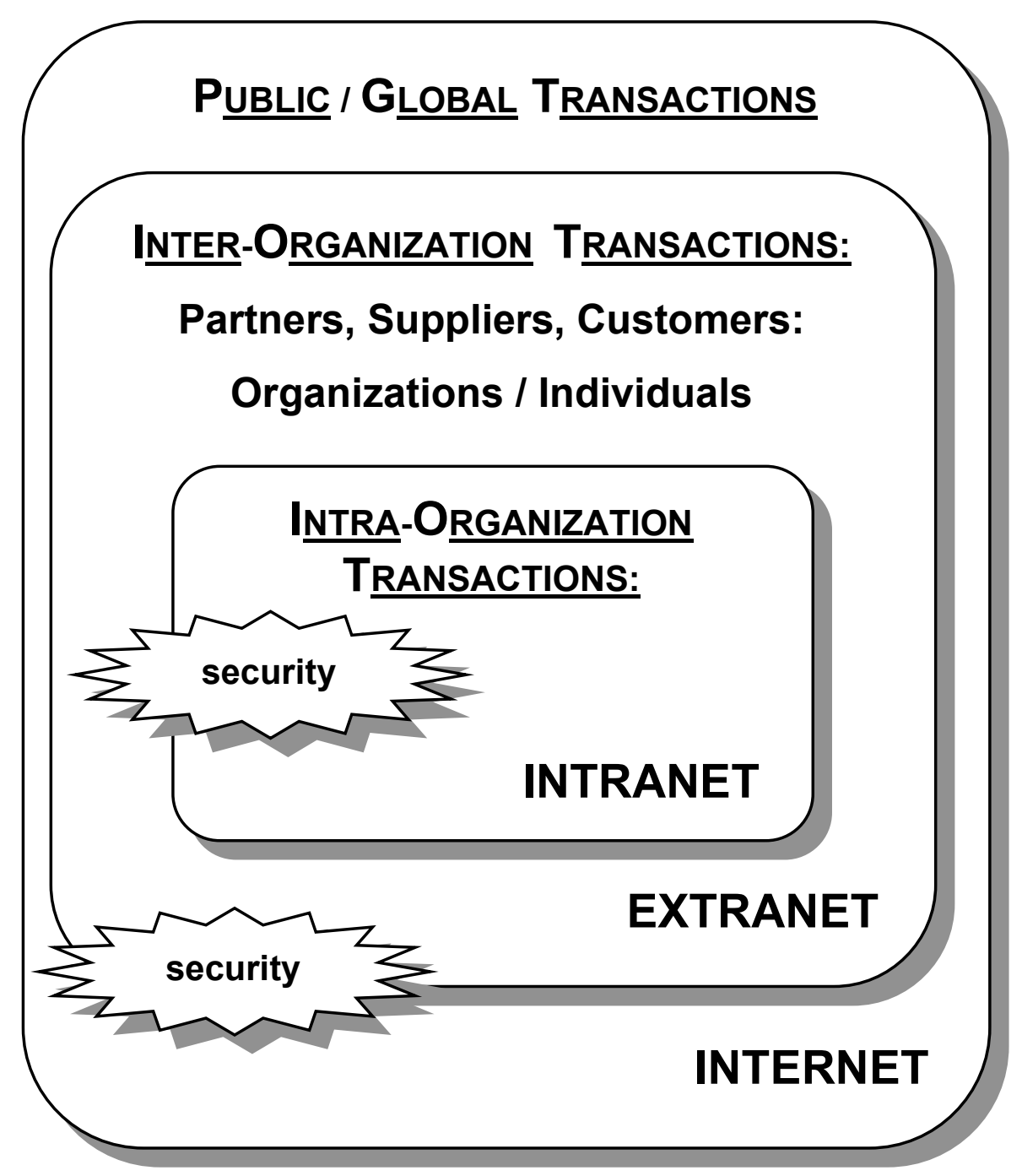

Figure 3: A multi-level functional view of e-business

The “development STOPE” profile, described above, provides a comprehensive base for the development of e-business in various countries and organizations. It gives an understanding of the various elements involved on the one hand, and it provides a reference framework for planning, and for the evaluation of the development state, at different times, on the other.

\section{Development Guidelines}

The e-business development guidelines presented here are associated with the elements of the above profile, and are considered to be of three integrated dimensions.

- The first dimension is concerned with providing "what is required" in order to enable the target development to take place. 


\section{E-BUSINESS DEVELOPMENT: A STRATEGIC VIEW}

- The second dimension is associated with considering "where to look for support", that is from the specialized organizations that may support the target development.

- The last dimension is concerned with "how to plan" for the development, that is the strategic plans that need to be identified.

\section{Requirements}

The basic requirements that enable the development of e-business include the following.

- The availability of "knowledge" in e-business. Such knowledge would include general awareness of the benefits of e-business, and the importance of using it. It would also include knowledge on how to use it, and make its benefits a reality, in addition to specialized knowledge on its management and future development.

- The availability of the "technology" that supports e-business. In this respect the four layers of e-business technology, discussed above, should be taken into account.

- The "need" for e-business development, in the organization concerned, for specific objectives such as promoting competitiveness, integration with other organizations, in addition to other possible objectives.

- The potential "cooperation" with other organizations so that e-business can achieve its interorganization objectives.

- The availability of "funds" for investment in e-business development. It should be noted that by using e-business, the investment will pay back from the resulting efficiency (Jamal-Aldeen and Al-Dheelaan 1999).

- The availability of the right "people" including decision makers with awareness, vision and drive, trained users, and qualified IT professionals.

- The need to "redesign" the work flow and transactions of the organization concerned, and make efficient use of the e-business capabilities.

- The acceptance of the new rules of the e-business "environment" and its new "work culture".

- The need to "manage" continuous change that may result from the continuous progress of IT in general, and e-business tools and practices in particular.

It is clear that the above basic requirements are related to the e-business "development STOPE" profile of the previous section. In addition, these requirements can be supported by different organizations, at different levels, as will be discussed in the following.

\section{Support}

International, regional, and national organizations, with special functions and responsibilities, would support the development of e-business in public and private organizations. Such support would promote e-business development, and therefore it should be taken into account. The organizations providing the needed support are addressed in the following. 


\section{SAAD HAJ BAKRY}

$\diamond$ Organizations concerned with setting up "development policies" at the international, regional, and national levels. Examples of such organizations include the United Nations (UN), the European Union (EU), the Organization of African Unity (OAU), the Arab League (AL), the Gulf Cooperation Council (GCC), and the national planning departments associated with governments. Such organizations should support e-business development, as it contributes to economic development, like what the EU decided to do at the Lisbon summit meeting.

$\diamond$ "Knowledge" organizations, such as research, education, and training institutions; publishing and information media organizations, in addition to consulting organizations. These organizations can contribute to the development of e-business knowledge and experience, and to the promotion of awareness, and the provisioning of qualifications.

$\diamond$ Organizations concerned with "funding" development projects at various levels, such as the $\mathrm{WB}$, the IDB, in addition to various regional and national development banks. These organizations can support e-business development projects through direct funding, or through supporting useful e-business development studies in knowledge organizations.

$\diamond$ International and national technology "standards" organizations, such as the American National Standards Institute (ANSI), the Internet Architecture Board (IAB), the International Standards Organization (ISO), and the International Telecommunications Union (ITU). These organizations are responsible for setting up suitable standards for the e-business technology.

$\diamond$ International and national "professional" organizations including those associated with technology professionals such as the Institute of Electrical and Electronics Engineers (IEEE), the Institution of Electrical Engineers (IEE), and other technical institutions; and those associated with trade and industrial development such as the Chambers of Commerce and Industries (CCI) in different parts of the world. These organizations should cooperate with organizations in different fields to give them economic advice and technical support for their ebusiness development.

$\checkmark$ "IT companies" including IT production and IT services companies should provide fine ebusiness tools and services. They should also cooperate with the professional and standards organizations for the benefit of the e-business customers.

\section{Recommended Plans}

Recommended e-business development plans should make use of the support of the abovespecialized organizations, and should satisfy the requirements discussed earlier. Such plans are identified in the following, and illustrated in Figure 4.

- "Initiation plan" for setting up the e-business objectives, and its development directions.

- "Knowledge plans" for supporting awareness, education, training, and progress.

- "Technology plan" for dealing with the current e-business enabling technology and its future development.

- "Reengineering plan" for redesigning business processes, and regulations, according to the need of the organization concerned on the one hand, and the technology to be used on the other.

"Security plans" for dealing with the security requirements of the e-business at its different levels.

- "Staff plan" for dealing with the human resources requirements, and job specifications.

- "Funding plan" for the evaluation of cost, and for dealing with the funding sources.

- "Migration plan" for transition from the existing business to e-business without interruption.

- "Cooperation plans" for working with other business and support organizations. 


\section{E-BUSINESS DEVELOPMENT: A STRATEGIC VIEW}

- "Change management plan" for continuous improvements in response to continuous development and change, as explained in (Jamal-Aldeen and Al-Dheelaan, 1999), (Bakry, S.H. 1999).

- "Integration master plan" for integrating the above plans and creating harmony between them during implementation.

The above-recommended plans are of general nature. They would be useful for e-business development in any country, and for any organization.

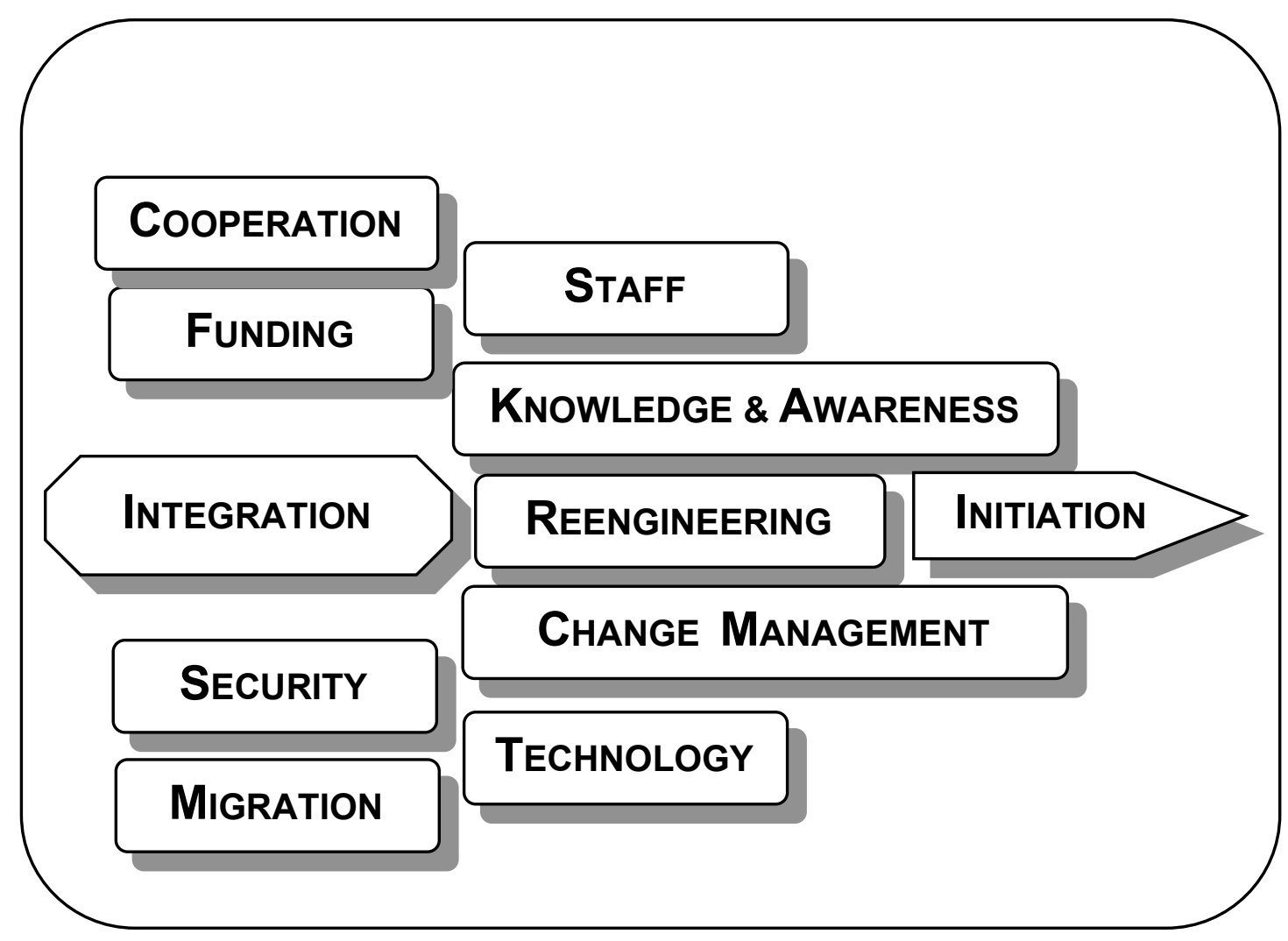

Figure 4: Recommended e-business development plans

\section{Conclusions}

This paper has attempted to build a strategic view for the development of e-business in three main stages. The first stage provided the necessary background, which illustrated the importance of e-business and its current progress. Using the background, the second stage built a profile that integrates the various elements associated with e-business development. Based on the profile, the third and last stage generated guidelines for the future development of e-business by highlighting the requirements, emphasizing potential support, and identifying recommended plans.

The background stage is useful for awareness, and for initiating drive toward e-business development. The profile has the advantage of providing an integrated understanding of the ebusiness architecture, which can be used as a development evaluation base. The development guidelines and the recommended plans have given answers to the questions what the requirements are, where support can be found, and how development can be planned. The three stages together would help countries and organizations plan for their own e-business development, so that they can enjoy its benefits including economic growth, competitiveness, and integration with customers and other organizations and with the world at large. 


\section{SAAD HAJ BAKRY}

\section{References}

BAKRY, SH., AL-DHELAAN, 1999. Planning information networks : the scope of the customer issues. International Journal of Networks Management; 9(1): 28-37.

BAKRY, SH., BAKRY, FH., 1999. Identifying information networks profiles for planning management. International Journal of Networks Management, 10(6): 315-322.

BECK, N. Excelerat: Growing in the New Economy, 1995, Harper Collins.

BUSINESS WEEK The global search for brain power : a shortage of programmers is hobbling technology growth., August 4, 1997.

BUSINESS WEEK, E.biz : a report on electronic business, December 13, 1999.

BUSINESS WEEK, Why the productivity revolution will spread. February 14, 2000.

CNN.com/2000/world/europe. March 24, 2000.

THE ECONOMIST, The net imperative : a survey of business and the Internet, June 26, 1999.

JAMAL-ALDEEN, R., BAKRY, SH., NOUH, A., 2000. Performance based evaluations of the tangible benefits of information networks. International Journal of Networks Management ; 10 (2): 91-101.

MAGUED DIOUF (Ministry of Industry, Senegal), NUN, A (Multimedia Super Corridor, Malaysia), and BAKRY, SH (IT Professor and Consultant). Contonou, Republic of Benin. Islamic Development Bank, Nov. 1998, Conference on Preparing the Ummah for the $21^{\text {st }}$ century : Promotion of Information Technology for Development.

HAMMER, M., CHAMPY, J., 1993. Reengineering the Corporation. Harper Business (Collins).

INFODEV: World Bank. Internet Web Site: www.worldbank.org. E-Mail : infodev@worldbank.com.

KRISHNAN, S. IT Democracy in India, April 26 1999, INFORMATION WEEK, Issue: 731, www.techweb.com/se/.

LINSTONE, HA. September 1994, New era-new challenge. International Journal of Technology Forecasting abd Social Change, 47(1): 1-21.

ROGER, MR., 1983. Diffusion of Innovations, $3^{\text {rd }}$ Edition. The Free Press (Macmillan).

THE TECHNOLOGY ATLAS Team. August 1987, A framework for technology based national planning. International Journal of Technological Forecasting and Social Change, 32(1): 5-35.

JAMAL-ALDEEN, R., BAKRY, SH., NOUH, A. Analysis of the cost effectiveness of information networks. International Journal of Neworks Management: to appear.

Received 5 June 2001

Accepted 9 September 2001 